\title{
Shape-selective oxidation of primary alcohols using perruthenate-containing zeolites
}

\author{
Daniel L. Wu, Andrea P. Wight and Mark E. Davis* \\ Chemical Engineering, California Institute of Technology, Pasadena, CA 91125, USA
}

Received (in Purdue, IN, USA) 27th December 2002, Accepted 5th February 2003

First published as an Advance Article on the web 25th February 2003

Potassium perruthenate $\left(\mathrm{KRuO}_{4}\right)$, a known, effective oxidant for the conversion of primary and secondary alcohols into carbonyl compounds is impregnated into zeolite $\mathrm{X}$ and shown to be a shape-selective oxidant using benzyl alcohol (reacted) and pyrenemethanol (not reacted).

Oxidation of alcohols has been the focus of much research, especially the search for suitable catalysts that use more environmentally friendly oxidants than the typical organic peroxides or amine oxides. ${ }^{1}$ Catalytic systems, both homogeneous and heterogeneous, based on copper, ${ }^{2}$ ruthenium, ${ }^{3}$ palladium, ${ }^{4}$ rhodium, ${ }^{5}$ cobalt, ${ }^{6}$ and manganese, ${ }^{7}$ have been reported to oxidize various alcohols into the corresponding carbonyl compound using molecular oxygen as the oxidant. Ley and co-workers showed that tetra- $n$-propylammonium perruthenate (TPAP) can be a suitable homogeneous catalyst for the room temperature oxidation of primary and secondary alcohols with $N$-methyl-morpholine- $N$-oxide (NMO) as a co-oxidant. 8,9 Additionally, homogeneous TPAP can use molecular oxygen as a co-oxidant for alcohol oxidation. ${ }^{10}$ Heterogeneous oxidation catalysts have also been prepared by supporting the perruthenate anion on polymeric resins ${ }^{11,12}$ and inorganic supports ${ }^{13}$ via anion exchange with potassium perruthenate $\left(\mathrm{KRuO}_{4}\right)$. The heterogeneous catalysts oxidize alcohols, using either $\mathrm{NMO}^{11}$ or molecular oxygen ${ }^{13}$ as a co-oxidant. Other methods of immobilizing and recycling perruthenate catalysts have been reported also, e.g., in ionic liquids ${ }^{14}$ or sol-gel materials, ${ }^{15}$ using either $\mathrm{NMO}^{14}$ or molecular oxygen ${ }^{14,15}$ as co-oxidants.

Here, we describe the first use of perruthenate in a zeolite support, and show its use as a recyclable, shape-selective oxidant in the room temperature oxidation of primary alcohols to aldehydes. Zeolites are known for their uniform pore size and ability to perform shape-selective catalysis. They also have superior chemical and thermal stability compared to polymeric supports. By confining the perruthenate anion within the zeolite void space, it should be possible to create a solid that is stable to regeneration and also able to discriminate between reactant substrates on the basis of molecular size. Additionally, these oxidizing solids will likely be compatible with other types of catalysts such as enzymes and organometallic complexes to allow the combinations of catalyst systems for performing multiple reactions within the same vessel. This is because the zeolite will isolate the oxidation function from contact with the other catalysts that would themselves be oxidized by perruthenate.

Na-X (FAU) zeolite was purchased from Strem Chemicals $\left(\mathrm{Na}_{88} \mathrm{Si}_{104} \mathrm{Al}_{88} \mathrm{O}_{384} \cdot 220 \mathrm{H}_{2} \mathrm{O}, 7.4 \AA\right.$ pore diameter, $\left.1.18 \mathrm{Si} / \mathrm{Al}\right)$. The Na-X was ion-exchanged to the potassium form $(\mathrm{K}-\mathrm{X})$ with $0.1 \mathrm{M}$ potassium hydroxide $(\mathrm{KOH})$ in four batch exchange steps (the final exchange was for 4 days). The K-X (1.261 g) was D dehydrated at $200^{\circ} \mathrm{C}$ for $2 \mathrm{~h}$ under vacuum to remove adsorbed water prior to the impregnation of perruthenate. A solution of $\mathrm{KRuO}_{4}$ (Alfa Aesar) in methanol or acetone as solvent $(0.259 \mathrm{~g}$ $\mathrm{KRuO}_{4}, 1.3 \mathrm{mmol}, 50 \mathrm{~mL}$ solvent) was then added to the dried $\mathrm{K}-\mathrm{X}$ and allowed to stir for several hours to permit the perruthenate to diffuse into the pore space. The solvent was then evaporated under flowing argon overnight to yield $\mathrm{Ru}-$ impregnated K-X (Ru-FAU). Loadings of the perruthenate were varied from $2 \mathrm{Ru}$ atoms/supercage (Ru-FAU-2) to $10 \mathrm{Ru}$ atoms/ supercage (Ru-FAU-10). The impregnated zeolites were characterized by UV-visible spectra (Cary 3G UV-visible Spectrophotometer), nitrogen adsorption isotherms (collected at 77 $\mathrm{K}$ on an Omnisorp 100 analyzer), thermogravimetric analysis (Netzsch STA 449C) and XPS (performed by the Chevron Research and Technology Co.).

The impregnated solids were tested as oxidants for the conversion of benzyl alcohol $\mathbf{1}$ to benzaldehyde $\mathbf{2}$ and 1-pyrenemethanol $\mathbf{3}$ (too large to enter pores of zeolite) to 1-pyrenecarboxaldehyde 4 (Scheme 1). The reactions were performed at room temperature under argon atmosphere in dichloromethane (DCM) or dichloroethane (DCE) as solvent. The reaction yield was monitored by GC (HP 5890 Series II, with a HP-5 capillary column, $30 \mathrm{~m} \times 0.25 \mathrm{~mm} \times 0.25 \mu \mathrm{m}$ ), using biphenyl as an internal standard (benzyl alcohol, 1-pyrenemethanol, biphenyl, DCM, and anhydrous DCE were obtained from Aldrich). DCM was dried and de-gassed by refluxing with calcium hydride and distillation under Ar. DCE and benzyl alcohol were dried over activated molecular sieves (4 Å, Advanced Specialty Gas Equipment) and then de-gassed by 3 freeze-pump-thaw cycles under dry nitrogen.

Results from reacting benzyl alcohol are summarized in Table 1 (aldehyde is the only product observed). A heterogeneous slurry of $\mathrm{KRuO}_{4}$ in $\mathrm{DCM}$ oxidizes the alcohol to benzaldehyde giving a yield of $95 \%$ at 24 hours. Ru-FAU-2 gave a $3 \%$ yield of $\mathbf{2}$ in the first 24 hours of reaction and increased to $8 \%$ after 76 hours of reaction. With a higher loading of $\mathrm{Ru}, \mathrm{Ru}-\mathrm{FAU}-10$ gave yields of 10 and $19 \%$ over 24 and 48 hour periods, respectively. K-X shows no activity for the oxidation. Benzyl alcohol can readily access the pore space of zeolite- $\mathrm{X}$ and react with the $\mathrm{KRuO}_{4}$ impregnated within the void space. However, at room temperature, the reaction rate

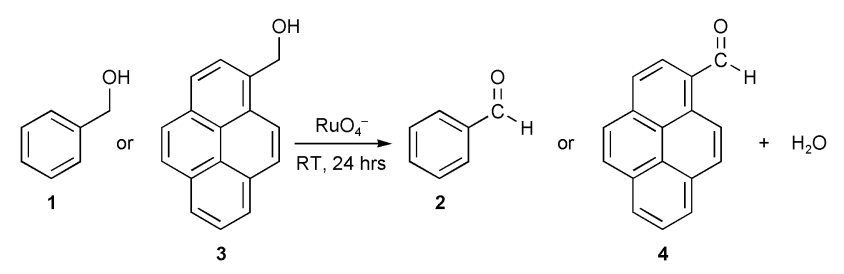

Scheme 1

Table 1 Oxidation of benzyl alcohol 1 over Ru-containing materials (1 mmol 1: $1.5 \mathrm{mmol} \mathrm{Ru}$, in $25 \mathrm{~mL} \mathrm{DCM}$ )

\begin{tabular}{llc}
\hline Material & Reaction time/h & Yield of $\mathbf{2}(\%)^{a}$ \\
\hline $\mathrm{KRuO}_{4}$ & 24 & 95 \\
Ru-FAU-2 & 24 & 3 \\
& 76 & 8 \\
$\mathrm{Ru}-\mathrm{FAU}-10$ & 24 & 10 \\
& 48 & 19 \\
$\mathrm{~K}-\mathrm{X}$ & 24 & $<0.02$ \\
$\mathrm{CPG}-\mathrm{P}+\mathrm{RuO}_{4}-$ & 27 & 68 \\
$\mathrm{CPG}-240$ & 24 & 0 \\
${ }^{a}$ Relative to moles of $\mathbf{1 .}$ & & \\
\hline
\end{tabular}


could be limited by slow diffusion of benzyl alcohol within the microporous void spaces. To test for this effect, a mesoporous solid was prepared by ion-exchanging $\mathrm{KRuO}_{4}$ onto controlled pore glass (CPG-240, 240 A pore diameter) that was functionalized with quaternary phosphonium chloride moieties (similar to work by Bleloch et al. in the ammonium-functionalized MCM-41 system). ${ }^{13}$ The $\mathrm{RuO}_{4}{ }^{-}$exchanged onto $47 \%$ of the phosphonium groups to give $\mathrm{CPG}-\mathrm{P}^{+} \mathrm{RuO}_{4}-$ that contained 0.27 mmol $\mathrm{RuO}_{4}-/ \mathrm{g}$ solid. The mesoporous material should have minimal diffusion limitations and produced $68 \%$ yield of 2 in 27 hours of reaction (CPG-240 was not active for the oxidation of benzyl alcohol). Thus, some effects of diffusion in the zeolite catalysts are likely.

The shape-selective nature of the Ru-FAU solid was demonstrated by testing for the reaction of pyrenemethanol 3 (Table 2). A DCE slurry of $\mathrm{KRuO}_{4}$ gave a $100 \%$ yield of $\mathbf{4}$ in 72 hours. Ru-FAU-2 shows no activity towards oxidation of $\mathbf{3}$ even after 120 hours of contact. Ru-FAU-10 shows slight activity ( $2 \%$ after 45 hours), but this is likely due to some amount of $\mathrm{KRuO}_{4}$ on the surface of the zeolite (see below). The mesoporous $\mathrm{CPG}-\mathrm{P}^{+} \mathrm{RuO}_{4}{ }^{-}$, that has sufficient pore size for adsorption of pyrenemethanol, gave $100 \%$ yield of $\mathbf{4}$ in 24 hours. Like with benzyl alcohol, neither K-X or CPG-240 showed any activity. Thus, Ru-FAU is able to oxidize alcohols into aldehydes in a shape-selective manner.

$\mathrm{KRuO}_{4}$ (neat) shows a broad absorbance in the UV-visible spectrum from 300-330 nm. K-X, CPG-240, and $\mathrm{RuO}_{2}$ (the fully reduced form of $\mathrm{RuO}_{4}^{-}$) have no absorbances over the UV-visible spectrum in the range of 200-700 nm. After Ru impregnation, the presence of $\mathrm{KRuO}_{4}$ can be observed by an absorbance at 300-330 nm in Ru-FAU-2. Nitrogen sorption data show that the zeolite pore space at high $\mathrm{Ru}$ loadings is greatly diminished. Ru-FAU-2 has a void volume of $0.231 \mathrm{cc}$ $\mathrm{g}^{-1}$, similar to the value for $\mathrm{K}-\mathrm{X}$ of $0.253 \mathrm{cc} \mathrm{g}^{-1}$ (void volumes are reported as $\mathrm{cc}$ of liquid nitrogen adsorbed per gram of dry solid). However, Ru-FAU-10 has a void volume of only 0.030 $\mathrm{cc} \mathrm{g}^{-1}$. The bulk composition of Ru-FAU-2 and Ru-FAU-10 are 0.18 and $0.80 \mathrm{Ru} / \mathrm{Si}(\mathrm{mol} / \mathrm{mol})$, respectively. XPS of the superficial area (surface plus several cages in depth) of each RuFAU sample showed that the composition near the surface of the zeolites was 0.173 and $18.33 \mathrm{Ru} / \mathrm{Si}$, for Ru-FAU-2 and $\mathrm{Ru}-$ FAU-10, respectively. Thus, Ru-FAU-10 has significantly more $\mathrm{Ru}$ in the superficial region and suggests that some $\mathrm{Ru}$ could be on the exterior surface of the zeolite. This result is consistent with the reactivity observed from Ru-FAU-10 with 1-pyrenemethanol.

In the reactions described above, the supported $\mathrm{RuO}_{4}{ }^{-}$was used in stoichiometric amounts with no additional co-oxidant added to observe the activity of the $\mathrm{RuO}_{4}{ }^{-}$species. In order to have a true catalyst, co-oxidants could be added or cyclic

Table 2 Oxidation of 1-pyrenemethanol $\mathbf{3}$ over Ru-containing materials (1 mmol 3: $1.5 \mathrm{mmol} \mathrm{Ru}$, in $5 \mathrm{~mL}$ DCE)

\begin{tabular}{lcc}
\hline Material & Reaction time/h & Yield of $\mathbf{4}(\%)^{a}$ \\
\hline $\mathrm{KRuO}_{4}$ & 24 & 89 \\
& 72 & 100 \\
$\mathrm{Ru}-\mathrm{FAU}-2$ & 120 & 0 \\
$\mathrm{Ru}-\mathrm{FAU}-10$ & 24 & 1 \\
& 45 & 2 \\
$\mathrm{~K}-\mathrm{X}$ & 24 & 0 \\
$\mathrm{CPG}-\mathrm{P}^{+} \mathrm{RuO}_{4}{ }^{-}$ & 24 & 100 \\
$\mathrm{CPG}-240$ & 24 & 0 \\
${ }^{a}$ Relative to moles of $\mathbf{3 .}$ & & \\
\hline
\end{tabular}

Table 3 Regeneration and recycling of Ru-FAU-2 (1 mmol 1:1.5 mmol Ru, in $5 \mathrm{~mL}$ DCE)

\begin{tabular}{lll}
\hline Material & $\begin{array}{l}\text { Reaction } \\
\text { time/h }\end{array}$ & $\begin{array}{l}\text { Yield of } \\
\mathbf{2}(\%)^{a}\end{array}$ \\
\hline & 24 & 3 \\
As-made Ru-FAU-2 & 76 & 8 \\
Spent Ru-FAU-2 (without regeneration) & 24 & 1 \\
Spent Ru-FAU-2 regenerated 35 mL min ${ }^{-1}$ flowing & & 3 \\
$\mathrm{O}_{2}, 100{ }^{\circ} \mathrm{C}, 3$ h & 24 & 3 \\
\begin{tabular}{l} 
Relative to moles of $\mathbf{1 .}$ \\
\hline
\end{tabular} & & \\
\hline
\end{tabular}

operation involving regeneration of the active site, $\mathrm{RuO}_{4}^{-}$, on the spent solid could be done. In addition, it would be desirable to use an economical oxidant, such as molecular oxygen, as the co-oxidate or to perform the regeneration. Here, the Ru-FAU-2 solid was tested for regeneration in oxygen. The results are illustrated in Table 3. As described above, as-made Ru-FAU-2 showed 3\% yield of 2 in $24 \mathrm{~h}$ of reaction. After isolating the spent solid from the reaction, no absorbance was observed at 300-330 nm in the UV-visible spectrum. The spent solid showed little activity (1\% yield) in a subsequent reaction with $\mathbf{1}$. The spent solid was then regenerated at elevated temperature with flowing oxygen for $3 \mathrm{~h}$. After the spent solid was regenerated at $100{ }^{\circ} \mathrm{C}$ for $3 \mathrm{~h}$, the activity of the recycled material was at levels observed from the fresh solid (3\% yield after $24 \mathrm{~h}$ ) and the UV-visible spectrum revealed the absorbance in the 300-330 $\mathrm{nm}$ range. Thus, the spent Ru-FAU-2 solid can be regenerated at $100{ }^{\circ} \mathrm{C}$ in oxygen and recycled to oxidize benzyl alcohol. While the reported yields are low, variations in temperature and solid amounts will certainly provide for higher conversions in shorter reaction times. Here, we provide results leading to the proof of concept and not optimal performance.

D. L. W. and A. P. W. acknowledge support from a California Institute of Technology Summer Undergraduate Research Fellowship and a National Science Foundation Graduate Fellowship, respectively.

\section{Notes and references}

1 B. M. Choudary, M. L. Kantam and P. L. Santhi, Catal. Today, 2000, 57, 17.

2 I. E. Marko, P. R. Giles, M. Tsukazaki, S. M. Brown and C. J. Urch, Science, 1996, 274, 2044

3 K. Yamaguchi and N. Mizuno, Angew. Chem., Int. Ed., 2002, 41, 4538.

4 T. F. Blackburn and J. Schwartz, J. Chem. Soc., Chem. Commun., 1977, 157.

5 J. Martin, C. Martin, M. Faraj and J.-M. Bregeault, Nouv. J. Chim., $1984,8,141$

6 T. Yamada and T. Mukaiyama, Chem. Lett., 1989, 519.

7 Y. C. Son, V. D. Makwana, A. R. Howell and S. L. Suib, Angew. Chem., Int. Ed., 2001, 40, 4280.

8 W. P. Griffith, S. V. Ley, G. P. Whitcombe and A. D. White, J. Chem. Soc., Chem. Commun., 1987, 1625.

9 S. V. Ley, J. Norman, W. P. Griffith and S. P. Marsden, Synthesis, 1994, 639.

10 R. Lenz and S. V. Ley, J. Chem. Soc., Perkin Trans. 1, 1997, 3291.

11 B. Hinzen and S. V. Ley, J. Chem. Soc., Perkin Trans. 1, 1997, 1907.

12 B. Hinzen, R. Lenz and S. V. Ley, Synthesis, 1998, 977.

13 A. Bleloch, B. F. G. Johnson, S. V. Ley, A. J. Price, D. S. Shephard and A. W. Thomas, Chem. Commun., 1999, 1907.

14 S. V. Ley, C. Ramarao and M. D. Smith, Chem. Commun., 2001 2278.

15 M. Pagliaro and R. Ciriminna, Tetrahedron Lett., 2001, 42, 4511. 